\title{
Article \\ Cationic Curing of Epoxy-Aromatic Matrices for Advanced Composites: The Assets of Radiation Processing
}

\author{
Guillaume Ranoux, Gabriela Tataru (D) and Xavier Coqueret *(D)
}

check for

updates

Citation: Ranoux, G.; Tataru, G.;

Coqueret, X. Cationic Curing of

Epoxy-Aromatic Matrices for

Advanced Composites: The Assets of

Radiation Processing. Appl. Sci. 2022,

12, 2355. https://doi.org/10.3390/

app12052355

Academic Editors:

Dorota Swiatla-Wojcik,

Yosuke Katsumura and Radosław

A. Wach

Received: 6 January 2022

Accepted: 22 February 2022

Published: 24 February 2022

Publisher's Note: MDPI stays neutral with regard to jurisdictional claims in published maps and institutional affiliations.

Copyright: () 2022 by the authors Licensee MDPI, Basel, Switzerland. This article is an open access article distributed under the terms and conditions of the Creative Commons Attribution (CC BY) license (https:// creativecommons.org/licenses/by/ $4.0 /)$.
Institut de Chimie Moléculaire de Reims, Université de Reims Champagne Ardenne, CNRS UMR 7312 51097 Reims, France; guillaume.ranoux@univ-reims.fr (G.R.); gabriela.tataru@univ-reims.fr (G.T.)

* Correspondence: xavier.coqueret@univ-reims.fr

Featured Application: Out-of-autoclave curing of epoxy matrices using high-energy radiation presents specific features and advantages over thermosetting technology.

\begin{abstract}
Cross-linking polymerization of multifunctional aromatic monomers initiated by exposure to high energy radiation continues to be explored as a promising alternative to thermal curing for the production of high-performance composite materials. High-energy radiation processing offers several advantages over thermosetting technology by allowing for fast and out-of-autoclave curing operations and for its adaptability in the manufacturing of large and complex structures at reduced energy costs. The present article covers the basic aspects of radiation curing by cationic polymerization of epoxy resins, providing a status report on recent investigations conducted in our group to improve the properties of epoxy matrices and gain better control over the process for producing composites. A selection of results based on blends prepared with different composition of epoxy aromatics, transfer agents, thermoplastic toughening agents and onium salt initiators exemplifies the importance of the composition on polymerization kinetics and on the properties of resulting materials. The superiority of radiation-triggered polymerization-induced phase separation of thermoplastic additives is emphasized by the obtained morphology of toughened materials. The low initial temperature and fast curing of the reactive blends limits the expansion of phase-separated thermoplastic domains, resulting in an enhancement of the toughness.
\end{abstract}

Keywords: epoxy resins; radiation curing; cationic polymerization; matrix toughening; composite materials

\section{Introduction}

The cross-linking polymerization of multifunctional aromatic monomers initiated by exposure to high-energy radiation continues to be explored as a promising alternative to thermal curing for the production of high-performance composite materials [1-4]. Highenergy radiation processing offers technical and economic advantages over thermosetting technology by allowing for fast and out-of-autoclave curing operation applicable to large and complex structures. It induces lower energy consumption and reduces development costs. Curing times are shorter, and resin formulations have longer shelf lives. The absence of highly volatile monomers reduces industrial and sanitary risks in the process. Radiationinduced curing is based on free radical and cationic chemistries commonly used for coating applications but not for the fabrication of massive composite parts, aside from some specific applications such as dental restorative materials [5]. As the typical thickness for structural composites ranges from few millimeters to centimeters and requires the use of shaping tools such as metal molds, the penetration of radiation, energy deposition and thermal effects are completely different from the standard conditions for 5 to $100 \mu \mathrm{m}$ thick strongly pigmented ink and paints cured by exposure to ultraviolet (UV) or electron beam (EB) radiation [6]. Moreover, the requirements in terms of thermophysical and mechanical properties as well as resistance to ageing under normal operation conditions are extremely different. This 
results in the need for deep knowledge on the relationships between resin composition, processing conditions and resulting properties for the cured matrix and at the interfaces between the matrix and fillers or fibers [7].

Epoxy resins form a large class of multifunctional monomers and prepolymers possessing reactive 1,2-epoxide functions (oxiranes). They are most commonly produced by the reaction under basic conditions of epichlorohydrin with various types of phenols, such as bis-phenol-A, leading to diglycidyl ether of bis-phenol A, DGEBA [8,9]. Another approach consists of the epoxidation of unsaturated hydrocarbon segments yielding various types of aliphatic and alicyclic epoxy monomers, such as epoxidized soya or linseed oils and cyclohexene-based esters [10]. These two sub-classes of epoxy resins are converted into solid networks by a variety of chemical mechanisms, yet with their specific reactivity and time-temperature conversion dependence due to blend composition and vitrification behavior.

Monomers and prepolymers fitted with two or more epoxy functions indeed form covalent networks either by step-growth polymerization or by chain-growth ring opening polymerization through cationic or anionic ring-opening reactions, the latter being essentially used for the linear polymerization of epoxy monomers having a simple structure (Scheme 1). The two modes of polymerization by chain and by stepwise growth proceed through drastically different mechanisms.

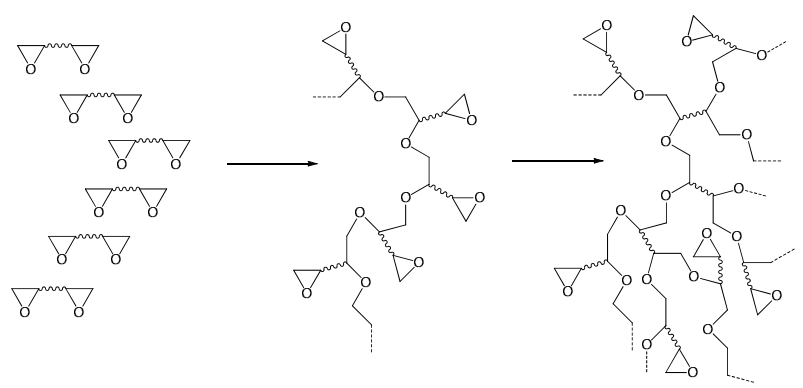

(a)

(b)
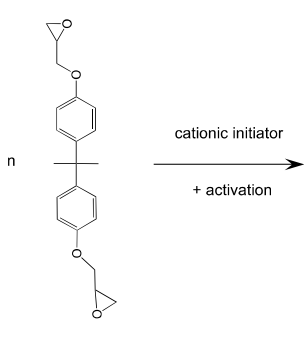

DGEBA

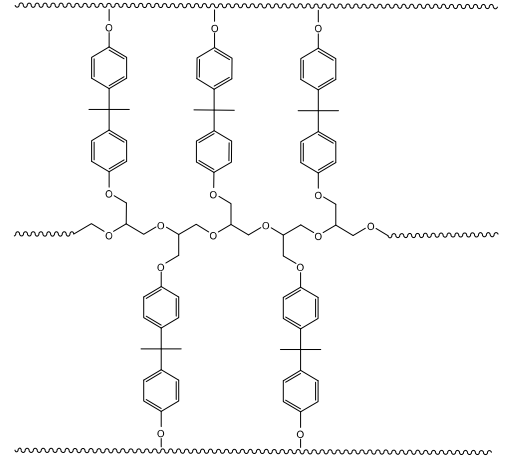

Scheme 1. Simplified representation of the cross-linking polymerization of diepoxides with formation of a covalent network (a) and its application to DGEBA monomer (b).

In ionic chain polymerization, there is no spontaneous chain termination such as the recombination of free radical species. Additionally, cationic polymerization is a pseudoliving process, with active centers which are accumulated in the medium as the initiation takes place (no steady state concentration). Those active centers survive and can continue propagation as long as monomer functions are still present, provided that mobility of the reactive species (cationic centers and monomers) is not restricted [11,12]. Once the production of new initiating centers has ceased, cationic polymerization continues by the so-called dark cure phenomenon [13], until the active centers are trapped in the glassy network or quenched by some inhibitor entering the material. This pseudo-living behavior enables further thermal activation giving rise to some beneficial post-cure effect $[14,15]$. As a consequence of the chain-growth mechanisms of epoxies initiated by Lewis or Brønsted acids, it is possible to control the polymerization process at the different stages: from the initiation to the propagation either by the active chain end mechanism (ACE), where the neutral monomer adds to the cyclic onium chain end by a nucleophilic attack, or by the activated monomer (AM), where a stable hydroxylic terminal group adds to a protonated monomer, with the possibility of forcing transfer reactions which may favorably affect the architecture and the cross-link density of the formed network (Scheme 2).

Most of the industrial solutions are currently based on robust systems that polymerize upon exposure to an energetic stimulus by activating latent onium salt initiators that are 
sensitive to high temperatures or to different types of radiation (UV-visible, accelerated electrons, $\mathrm{X}$-rays and $\gamma$-rays) [15-17].

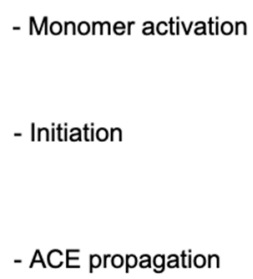

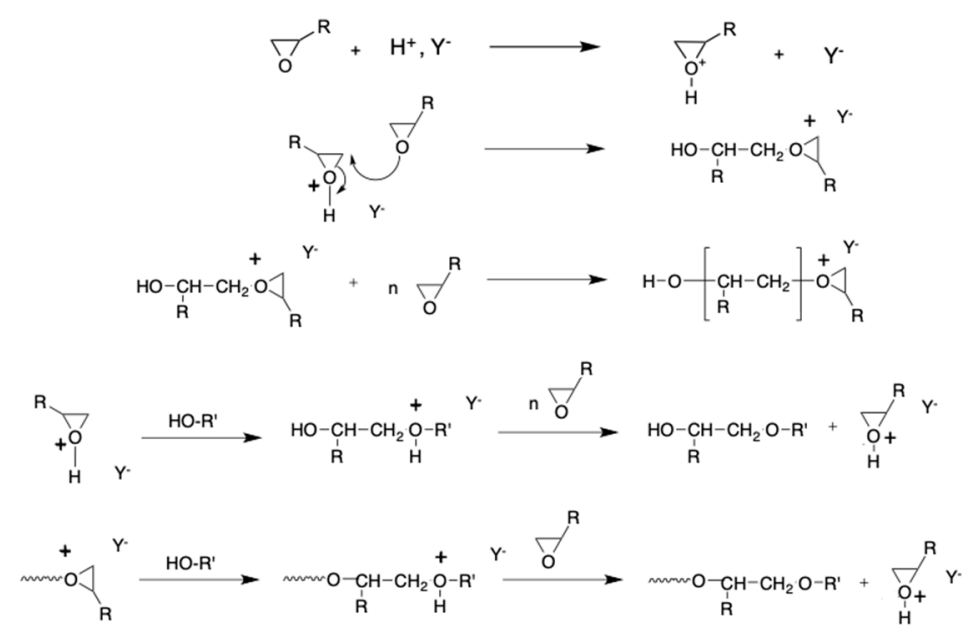

Scheme 2. Sequence of equations detailing the mechanism of cationic chain polymerization of epoxides initiated by a Brønsted acid HY.

The cationic chain polymerization process which was selected for our current work will be preferably triggered by exposure to high-energy irradiation which efficiently induces the polymerization of epoxy resins. The choice for an appropriate acceleration voltage is primarily guided by the need for sufficient penetration of the electron beam into the uncured material shaped by the mold and associated tooling. The plots of Figure 1 represent the simulated deposition of energy in a material of unit density as a function of the EB energy. This shows that composite materials of thicknesses or cross-sections up to some centimeters can be treated with a rather uniform energy deposition, provided that the mold itself does not abate dramatically the incident beam. This is actually a strong advantage of this technology operated initially at room temperature (RT) and which does not to require strong and complex tools. Moreover, lower energy EB (few hundreds eV) can, however, be used for laboratory test experiments, particularly for filler-free resin samples or simple pre-impregnated fabrics which do not require metal casting tools.

Other processing parameters include the power of the accelerator and the features of the beam (scan rate and dimensions, pulse frequency and duration), which all affect the instant and time-average dose rate [18].

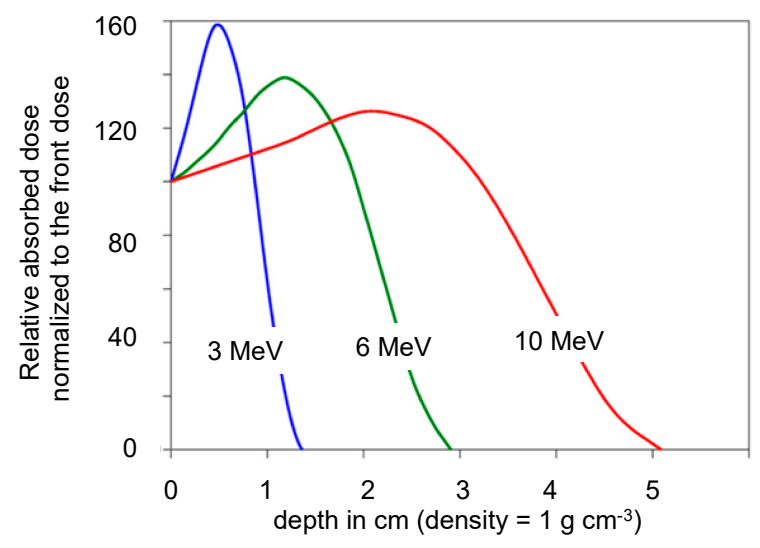

Figure 1. Simulated depth-dose distribution (expressed as percent relative of the front dose absorbed at the entrance face of an object exposed of unit density exposed to EB radiation of energy 3, 6 and $10 \mathrm{MeV}$ (adapted from Ref. [19]). 
The interaction between matter and the high-energy photons or particles is essentially a non-selective process producing randomly excited states, radical cations and thermalized electrons as the primary species. In organic materials, the primary species are essentially converted into free radicals. Long-lived cationic chain reactions due to carbenium or oxonium intermediates generated and evidenced at low temperature in ultra-pure epoxy monomers free from any initiator are unlikely. The high reactivity of cationic centers renders transfer and deactivation reactions very fast unless special conditions (purity of involved chemicals, low temperature) are maintained throughout the process. There are still debates on the precise mechanism of cationic initiation under EB irradiation; however, when irradiation is applied to epoxies formulated with onium salts, a reasonable description of the initiation is based on an electron transfer from the in situ generated free radicals (with appropriate reduction potential) or from thermalized electrons that reduce onium salts efficiently [18]. These mechanisms were confirmed by pulse radiolysis experiments on DGEBA in the presence of an iodonium salt $[17,20]$.

For this reason, onium salts, in particular diaryliodonium salts, which exhibit favorable redox properties in the presence of organic free radicals, are introduced in the epoxy formulations processed by high-energy radiation. As similar redox reactivity of iodonium and sulfonium redox agents plays a central role under alternative modes of activation, the thioxanthone-photosensitized reduction under exposure to UV-visible photoactivation, as well as the thermal decomposition of peroxides forming reductive free radicals, can be used for the purpose of comparison or for facilitating the preparation of test samples. This is summarized in Scheme 3 which illustrates the possible pathways to the cationic initiation of epoxide polymerization. It should be kept in mind that behind the mechanistic similarities in the chemical initiation mechanism and polymerization schemes, the actual temporal, spatial and physical conditions of these modes of activation are quite different, with significant differences in their applicability and in terms of the resulting material.

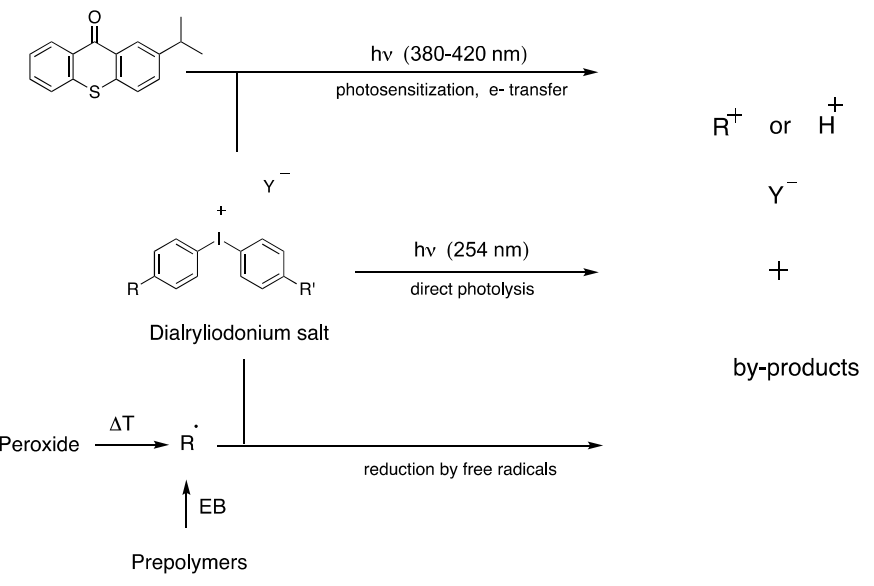

Scheme 3. General scheme representing the 3 modes of activation (UV, EB, thermal) of onium salts for generating carbo-cationic species or a proton which initiate the polymerization of epoxy monomers.

Epoxy resins cured by conventional step-growth mechanisms can be formulated and processed to yield a set of unique chemical and physical properties, including excellent chemical resistance, heat resistance, limited shrinkage on curing, high mechanical properties (strength and tenacity), low dielectric dissipation and good adhesion to polar substrates and filler [9]. The resulting networks find applications as adhesives and matrices in composites for aerospace, automotive, electronics, and packaging sectors. Serious limitations are nevertheless associated with the use of epoxy-based matrices cured by chain reaction. Network brittleness drives the need for new systems either based on revisited monomer chemistry or based on blending conventional monomers with reactive polymers [21]. This article covers the basic aspects of radiation curing by cationic polymerization of aromatic 
epoxies, and provides a status report on recent investigations implemented to improve composite properties and to enhance the overall control on the curing process.

We present here an overview of representative results obtained by curing radiationcurable formulations based on the aromatic epoxy resin DGEBA with an $n$ value close to zero, whereas in practice formulations containing DGEBA oligomers, epoxynovolak (EPN) and solid epoxy prepolymer DGEBA-Novolak-type can be formulated to adjust the initial viscosity, reactivity and modulus of the cured materials (Scheme 4a). In situ acid generation was achieved using commercial iodonium or sulfonium salts (Scheme $4 b$ ).
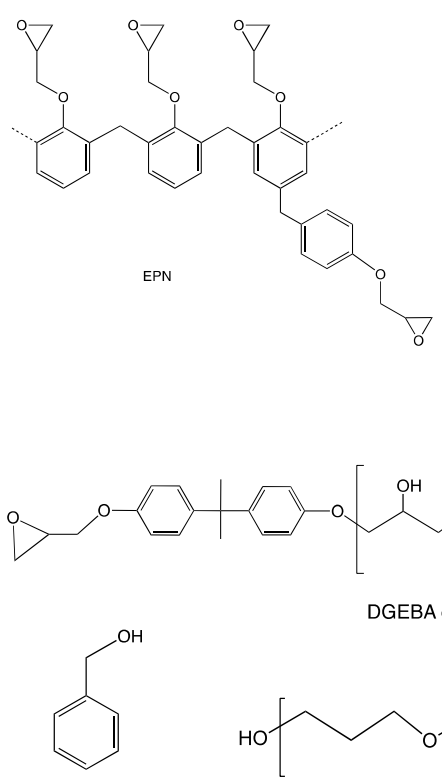

Benzyl alcoho

poly(THF)
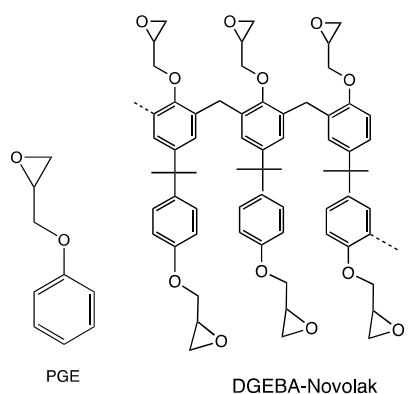

DGEBA-Novolak

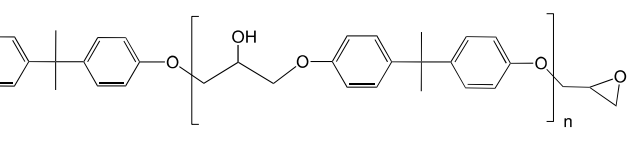

DGEBA oligomer<smiles>CCCCCC(C)(C)OCCCC(C)(C)C</smiles>

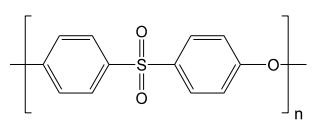

Polyethersulfone (PES)

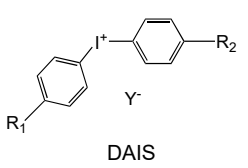

$\mathrm{R}_{1}=\mathrm{CH}_{3}, \mathrm{R}_{2}=\mathrm{CH}\left(\mathrm{CH}_{3}\right)_{2}$

$\mathrm{Y}^{-}=\mathrm{B}\left(\mathrm{C}_{6} \mathrm{~F}_{5}\right)_{4}^{-}, \mathrm{PF}_{6}{ }^{-}, \mathrm{AsF}_{6}{ }^{-}$or $\mathrm{SbF}_{6}$

(a)

(b)

Scheme 4. Chemical structure (a) of the epoxy aromatic monomer (phenylglycidylether (PGE)) and prepolymers, epoxynovolak (EPN), diglycidylether of bis-phenol A (DGEBA and DGEBANovolak), transfer agents (benzyl alcohol and poly(tetrahydrofuran)) and polyethersulfone (PES) as a thermoplastic toughener and (b) of the onium salts, diaryliodonium (DAIS) and triarylsulfonium salts (TASS) as initiators that were used in this study.

\section{Materials and Methods}

\subsection{Materials}

Diglycidyl ether of bis-phenol A, DGEBA (DER 330, Dow Chemical) was the base model epoxy resin used in this study. The onium salt initiators for EB initiation were cumyl-tolyl-iodonium tetrakis(pentafluorophenyl)borate (Bluesil PI2074, Bluestar Silicone), named DAIS-B and triarylsulfonium hexafluorophosphate (TAS-SbF ${ }_{6}$ ) and hexafluorophosphate $\left(\mathrm{TAS}-\mathrm{PF}_{6}\right.$ ) from Sigma-Aldrich. For UV curing at $385 \mathrm{~nm}, \mathrm{TAS}-\mathrm{SbF}_{6}$ was used for direct photoactivation. The desired amount of initiator was added to the resin and cautiously dissolved by mechanical stirring under exclusion of visible light. The samples were protected for moisture sorption at the different stages of their preparation.

Benzyl alcohol (BzOH), phenyl glycidyl ether (PGE) and poly(tetrahydrofuran)-diol (number-average MW = 250) and Luperox P were obtained from Sigma-Aldrich, France. PGE was stored over molecular sieves to minimize its moisture content. Unmodified silica powder (grade Millisil E6 with characteristic particle size $<150 \mu \mathrm{m}$ ) was obtained from Sifraco (Entraigues, France) and used as an inert filler after extensive dehydration for $24 \mathrm{~h}$ at $90^{\circ} \mathrm{C}$ in a ventilated oven for few test samples, as detailed in the section Results and Discussion. In these composite samples, the silica content was $60 \mathrm{wt}$ \%. Poly(ethersulfone) with the reference PES 3600P (low molecular weight, reduced viscosity 0.36 at $1 \% w / v$ in dimethylformamide) or PES 5003P (higher molecular weight, reduced viscosity 0.50 at $1 \%$ 
$w / v$ in dimethylformamide) from Sumitomo Chemical (Japan) was used as a toughening agent dissolved in the precursors of the epoxy matrices.

\subsection{Curing by Irradiation}

Unless otherwise stated, blends of epoxy resin, onium salts and selected additives were mixed in proportions expressed as $\mathrm{wt}-\mathrm{\%}$ of the final mixture.

Simple bar samples of controlled dimensions $(2 \mathrm{~mm}$ thick and $5 \mathrm{~mm}$ broad, $40 \mathrm{~mm}$ long) were obtained in silicon molds. Larger plates were prepared in aluminum molds assembled from $5 \mathrm{~mm}$ thick metal plates (from $10 \mathrm{~cm} \times 10 \mathrm{~cm}$ to $20 \mathrm{~cm} \times 30 \mathrm{~cm}$ ) coated with a thin layer of demolding agent and placed on both sides of a 1 to $4 \mathrm{~mm}$ thick rectangular metal spacer. The resin was poured into the molds through a special opening on the top surface and then degassed under vacuum $\left(100\right.$ mbars, $\left.80^{\circ} \mathrm{C}\right)$. The samples were exposed with their largest dimension perpendicular to the beam of a pulsed electron accelerator (10 MeV Circe II Linac, 20-30 kW) operated with a time-averaged dose rate of ca. $15 \mathrm{kGy} \mathrm{s}^{-1}$ (Ionisos facility, Chaumesnil, France). The dose was adjusted by changing the number of passes applied to the sample at 10, 25 or $50 \mathrm{kGy}$ per pass, as indicated in the text.

In some experiments, a Cu-constantan thermocouple was placed at the center of the sample to record the temperature profile in the resin during radiation processing.

Post-thermal treatments were performed in ovens set at the desired temperature.

\subsection{Infrared (NIR) Monitoring}

The extent of polymerization was determined by near infrared (NIR) spectroscopy performed with a Vertex 70 spectrometer (Bruker), based on transmission spectra recorded between 8000 and $4000 \mathrm{~cm}^{-1}$ with a spectral resolution of $4 \mathrm{~cm}^{-1}$. The decay of the epoxy band vibration at $4529 \mathrm{~cm}^{-1}$ was measured and normalized to the $4624 \mathrm{~cm}^{-1}$ aromatic C-H combination band. Monomer conversion $(\pi)$ was calculated according to Equation (1) [22]:

$$
\Pi=\left[1-\frac{R_{(t)}}{R_{(0)}}\right] \times 100 ; R_{(t)}=\frac{A b s_{4529 \mathrm{~cm}^{-1}}(t)}{A b s_{4524 \mathrm{~cm}^{-1}}(t)}
$$

Each measurement was triplicated by changing the position of the sample's probed zone. Conversion values were calculated from the resulting average.

\subsection{Structural Characterization of Cured Samples}

The monomer conversion $(\pi)$ was determined by near infrared spectroscopy performed with a Vertex 70 spectrometer (Bruker). Temperature-modulated differential scanning calorimetry (TMDSC) was performed on 5-10 mg samples of cured materials with a TA Instruments Q100 upgraded with the temperature-modulation option. Measurements were conducted from $30{ }^{\circ} \mathrm{C}$ to $250{ }^{\circ} \mathrm{C}$, at $1.5^{\circ} \mathrm{C} \cdot \mathrm{min}^{-1}$ with a modulation amplitude of $0.5^{\circ} \mathrm{C} \cdot \mathrm{min}^{-1}$ and a $90 \mathrm{~s}$ period. The glass transition temperature was determined from the position of the maximum of the reversing heat capacity derivative.

The thermomechanical properties were determined with a TA Instruments Q800 Dynamic Mechanical Analyzer. The analyses were carried out on cured sample rods (17.5 mm long, $10 \mathrm{~mm}$ broad, $2 \mathrm{~mm}$ thick) with a single cantilever clamp at $1 \mathrm{~Hz}$, a $30 \mu \mathrm{m}$ amplitude and a $3^{\circ} \mathrm{C} \cdot \mathrm{min}^{-1}$ ramp temperature.

Micrographs revealing the surface morphology of cryo-fractured samples were recorded using a JEOL7900F scanning electron microscope operated at $1.5 \mathrm{kV}$.

\subsection{Tensile Properties of Cured Samples}

$\mathrm{K}_{\mathrm{IC}}$ measurements were performed using the test methods of ISO 13586 with single edge notch bend specimen dimensions, $52.8 \mathrm{~mm} \times 6 \mathrm{~mm} \times 12 \mathrm{~mm}$, that was notched and pre-cracked according to the standard. Specimens were submitted to three-point bending test using a Zwick 1485 machine (5 tests for each material) [23]. 


\section{Results and Discussion}

We present here an overview of representative results obtained by curing radiationcurable formulations based on the aromatic epoxy resin DGEBA with an $\mathrm{n}$ value close to zero, whereas in practice formulations containing DGEBA oligomers, epoxynovolak (EPN) and solid epoxy prepolymer DEGEBA-Novolak-type, can be formulated to adjust the initial viscosity, reactivity and modulus of the cured materials (Scheme 4a). In situ acid generation was achieved using commercial iodonium or sulfonium salts (Scheme $4 b$ ). To adjust the reactivity and the cross-link density in the obtained networks, a monoepoxide, phenylglycidyl ether (PGE), as well as transfer agents such as benzylalcohol and poly(tetrahyrofuran)-diol (poly(THF)), were introduced in variable amounts into some formulations. To evaluate the reactivity and the thermophysical behavior of toughened matrices, a high-Tg thermoplastic, poly(ethersulfone) (PES), of limited molecular weight was dissolved into specific blends, whereas a powdered silica was used as mineral filler to perform preliminary tests on model composite materials.

\subsection{Monitoring of Epoxy Polymerization}

The extent of polymerization was determined at different stages of the curing process by near infrared spectroscopy. A representative series of spectra is shown in Figure 2a. The measurements performed on DGEBA samples containing various amounts of DAIS-B and cured with two passes of $50 \mathrm{kGy}$ can be compared to a spectrum of the uncured resin of the same thickness (Figure 2b). Using Equation (1), the conversion levels of epoxy groups were as high as $85,88,89$ and $95 \%$, for $0.125,0.25,0.50$ and $1.00 \mathrm{wt}-\%$ of iodonium salt, respectively. These results can be compared to the values measured from samples prepared with sulfonium TAS- $\mathrm{PF}_{6}$ and $\mathrm{TAS}-\mathrm{SbF}_{6}$, with the same concentration range and same radiation treatment of an overall dose of $100 \mathrm{kGy}$ (Figure 3). The two triaryl sulfonium salts appear much less efficient than DAIS-B. This is due to the decrease in reduction of potential properties of sulfonium $\left(\mathrm{E}^{\circ}\left(\mathrm{Ar}_{3} \mathrm{~S}^{+} / \mathrm{Ar}_{2} \mathrm{~S}+\mathrm{Ar}{ }^{\bullet} \simeq-1.2 \mathrm{~V}\right.\right.$ vs. $\left.\mathrm{SCE}\right)$ compared to the iodonium cation $\left(\mathrm{E}^{\circ}\left(\mathrm{Ar}_{2} \mathrm{I}^{+} / \mathrm{ArI}+\mathrm{Ar}\right) \simeq-0.8 \mathrm{~V}\right.$ vs. $\left.\mathrm{SCE}\right)[24,25]$.

a)

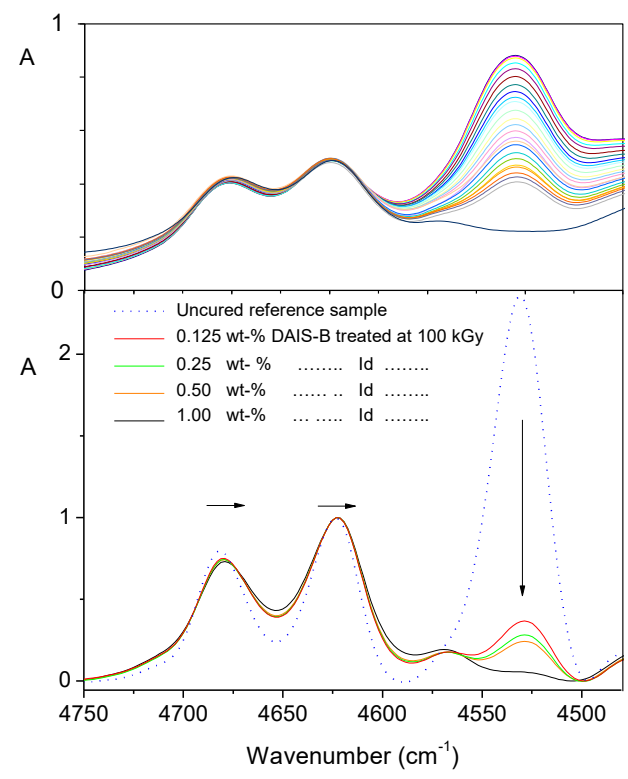

Figure 2. NIR monitoring of the polymerization of epoxy groups: (a) variation of epoxy absorbance at $4535 \mathrm{~cm}^{-1}$ upon $385 \mathrm{~nm}$ irradiation of DGEBA containing TAS-SbF 6 ( $1 \mathrm{wt}-\%$ ) for 0 to $230 \mathrm{~min}$ with an irradiance of $150 \mathrm{~mW} \mathrm{~cm}^{-2}$ and final post-curing for $30 \mathrm{~min}$ at $130{ }^{\circ} \mathrm{C}$; (b) DGEBA with various amounts of DAIS-B treated in $1 \mathrm{~mm}$ thick Al molds under EB with two passes of $50 \mathrm{kGy}$. 


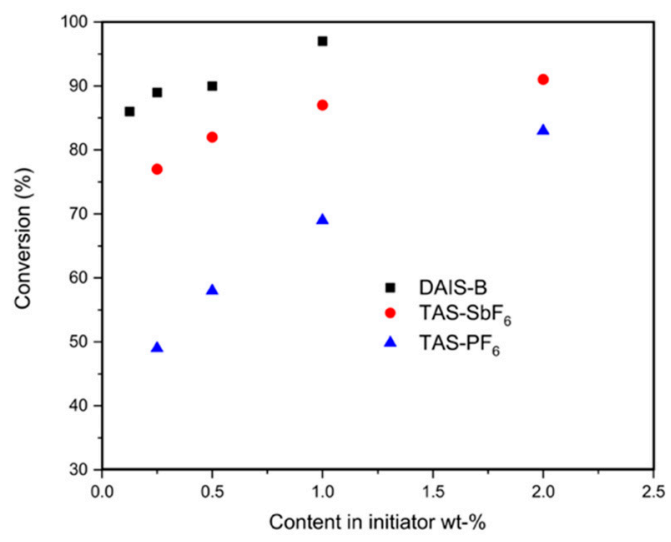

Figure 3. Dependence of epoxy conversion on the nature and content of onium salt in DGEBA after an overall treatment at $100 \mathrm{kGy}$ (2 times $50 \mathrm{kGy}, 1 \mathrm{~mm}$ thick plates), as measured by NIR transmission spectroscopy.

The strong influence of the nature of counter-anion, hexafluoroantimonate or hexafluorophosphate is clearly evidenced from the comparison between the two salts with the same sulfonium cation [26]. This confirms the utmost importance of the reduced nucleophilic character which limits ion pair interactions and favors propagation. For all systems, a common trend is the favorable influence of the absorbed dose and the initiator content, which lead to an expected increase of active center concentration, with a direct and positive effect on conversion. Thermal effects resulting from polymerization exothermicity, about $80 \mathrm{~kJ} \cdot \mathrm{mol}^{-1}$ for epoxy monomers, are also considerable in the rapid polymerization of large quantities of bulk monomers $[27,28]$.

\subsection{Thermal Effects upon Irradiation}

To apprehend more precisely the thermal effects associated with the so-called "room temperature" polymerization induced by radiation, thermocouples were placed in resin samples containing $0.5 \mathrm{wt}-\%$ of DAIS-B [29]. The $3 \mathrm{~cm}$ thick bulk sample with its $280-300 \mathrm{~g}$ of epoxy resin was conveyed under the electron beam to absorb $25 \mathrm{kGy}$ per pass. With an initial energy of $10 \mathrm{MeV}$, the electron flux goes through the sample with very limited attenuation, as illustrated by the plots of Figure 1. Energy deposition can be considered to be essentially uniform.

The recorded temperature profile (Figure 4) shows that after a short period of latency, during which the sample is warmed up by conversion of the incoming beam into heat while the first acidic species to be generated in situ are quenched by basic contaminants and moisture, the temperature in the irradiated sample rises up to $180^{\circ} \mathrm{C}$ within about $10 \mathrm{~s}$, the peak being observed as the sample has already moved away from the irradiation zone.

During the second and third pass, the temperature rise is limited, being only due to the absorption and conversion of radiation. Polymerization proceeds in almost adiabatic conditions. Polymerization seems to have been driven to completion. The kinetics of energy dissipation can be appraised from the very smooth slope of temperature decrease $150 \mathrm{~s}$ after the onset of irradiation.

More complex temperature profiles have been recorded during other experiments conducted with various contents in onium salt. The occurrence of vitrification between two consecutive passes may occur and block further reaction, resumption of the exposure to radiation being almost inefficient in a glassy matrix even if large amounts of unreacted epoxy functions are available for polymerization. Conversion measurements at various stages of the curing process are expected to bring additional information. 


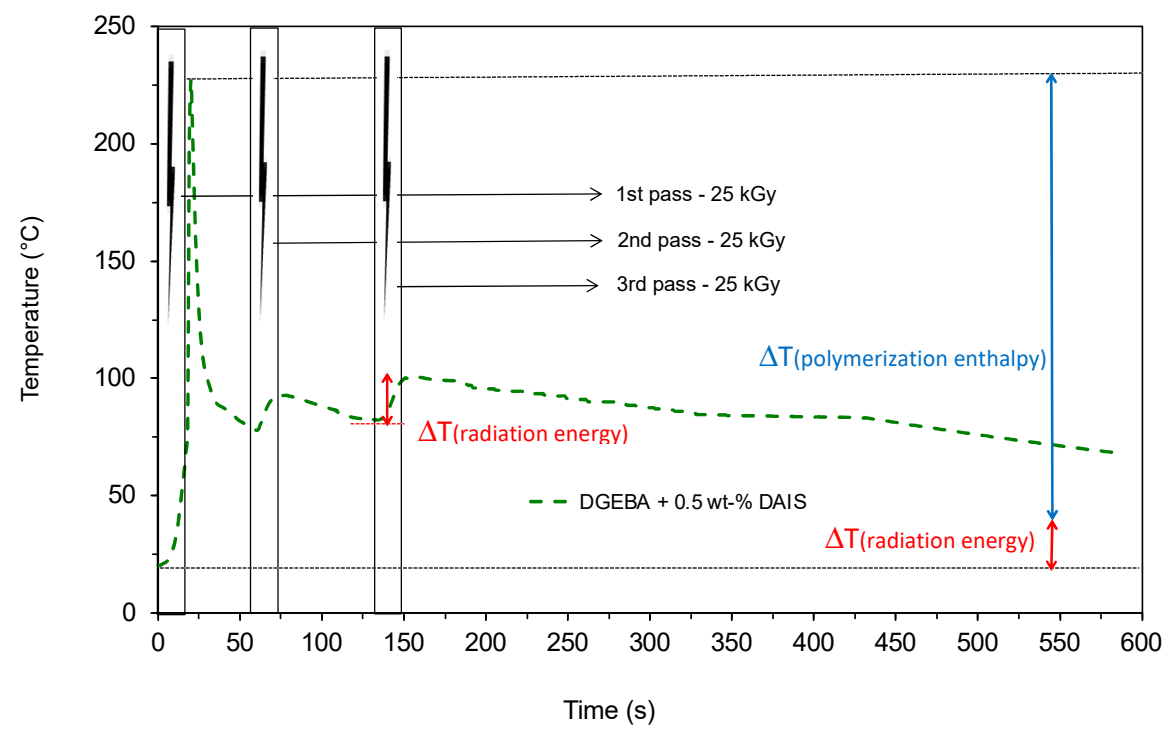

Figure 4. Temperature profiles recorded during the dynamic EB irradiation with 3 consecutive $25 \mathrm{kGy}$ passes of a $3 \mathrm{~cm}$ thick DGEBA resin sample containing $0.5 \mathrm{wt}-\%$ of DAIS-B.

\subsection{Dose Effects Combined and Thermal Treatments}

Using two initiators with a smoother reactivity than DAIS-B, we prepared and cured under various conditions two series of blends containing from 0.5 to $4 \mathrm{wt}-\%$ of sulfonium salts either with the $\mathrm{PF}_{6}{ }^{-}$or $\mathrm{AsF}_{6}{ }^{-}$counter-anion. Polymerization was induced by EB irradiation at $50 \mathrm{kGy}, 100 \mathrm{kGy}$, and $250 \mathrm{kGy}$ with optional thermal post-treatment at 190 or $250{ }^{\circ} \mathrm{C}$ for $4 \mathrm{~h}$.

The results represented in the bar graphs of Figure 5 confirm without surprise the higher efficiency of the hexafluoro-arsenate salt. It is worth noticing another important difference with respect to the combined effects of initiator concentration and strength of the curing treatment. The comparison is very instructive since Figure 5 a clearly shows that for a given content in onium salt, the harsher the treatment, the lower the increase of conversion, even if the content in unreacted epoxy groups is high. Here, experiments conducted at 190 and $250{ }^{\circ} \mathrm{C}$ in the presence of low or even high concentrations of hexafluorophosphate initiator allow to exclude the occurrence of vitrification phenomena between the stages of a curing treatment. This raises questions about the real living feature of the active centers in the presence of $\mathrm{PF}_{6}{ }^{-}$anions.
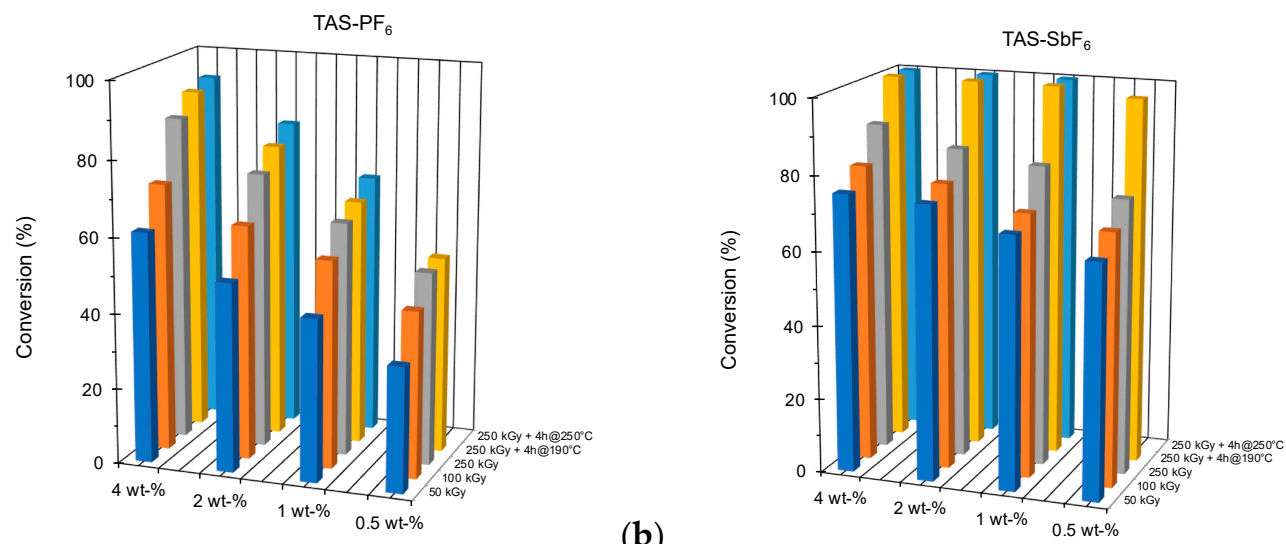

(b)

Figure 5. Influence of dose and thermal post-treatments on epoxy conversion of a DGEBA resin sample containing various amounts of sulfonium salts $(0.5$ to $4 \mathrm{wt}-\%)$ with $\mathrm{PF}_{6}{ }^{-}$(a) or $\mathrm{AsF}_{6}{ }^{-}$(b) counter-anion, after EB irradiation at $50 \mathrm{kGy}, 100 \mathrm{kGy}, 250 \mathrm{kGy}$ and subsequent thermal treatments at 190 or $250{ }^{\circ} \mathrm{C}$ for $4 \mathrm{~h}$. 
Contrastingly, with the hexafluoro-arsenate anion (Figure 5b), the rougher the treatment and post-curing were, the higher the increase in conversion. It seems that we are here benefiting from the accumulation of active centers and overcoming vitrification without significant loss of chemical reactivity.

\subsection{Material Properties}

The correlation between epoxy conversion and thermophysical properties of the cured matrices is the articulation between molecular structure and the solidification or hardening of reactive epoxy blends subject to polymerization. The thermomechanical spectra of Figure 6a recorded during the first ramp of the DMA analysis show the strong difference between the matrix cured at $10 \mathrm{kGy}$ and at the two higher doses (two times at $25 \mathrm{kGy}$ and four times at $25 \mathrm{kGy}$ ). The primary observations are explained by the progress of epoxy polymerization at higher doses or by the resumption of pseudo-living cationic polymerization while the thermal ramp of DMA analysis crosses the glass transition of the analyzed sample.

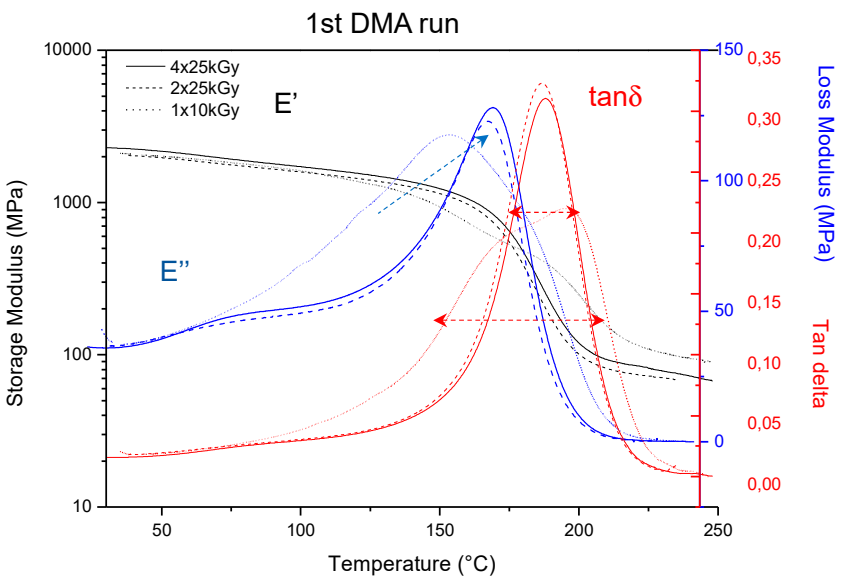

(a)

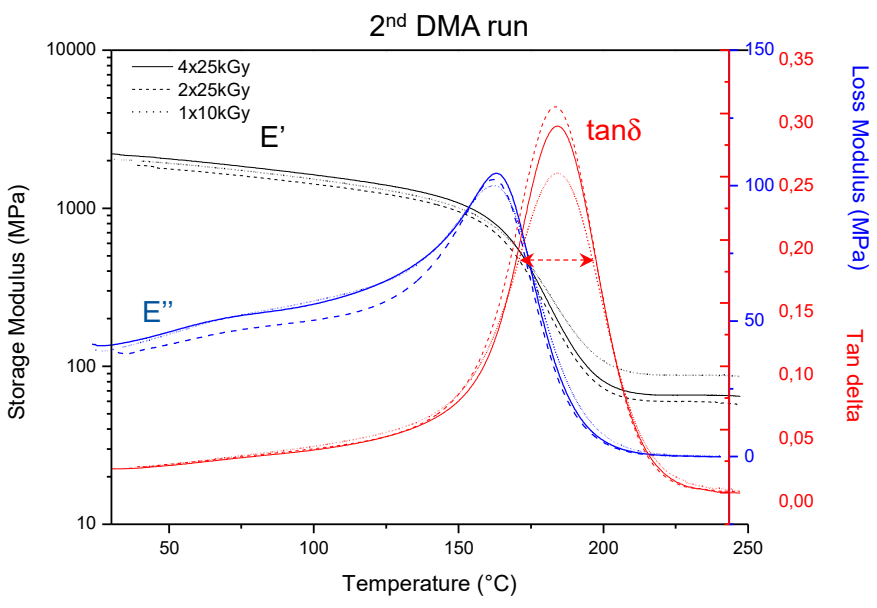

(b)

Figure 6. Influence of dose and repetition of the DMA run on the thermomechanical properties of a DGEBA resin sample containing $0.5 \mathrm{wt}-\%$ of DAIS-B after EB irradiation at $10,2 \times 25$ and $4 \times 25 \mathrm{kGy}$ : (a) first DMA run from RT to $230^{\circ} \mathrm{C}$; (b) second DMA run.

A slight decrease in the temperature of $\tan \delta$ maximum from $190^{\circ} \mathrm{C}$ to $188^{\circ} \mathrm{C}$ between the first and the second run is observed for samples cured at 50 and $100 \mathrm{kGy}$ (Figure 6b). Such a behavior, systematically observed in cured samples, has been discussed already in terms of relaxation of ion pair clusters [28]. There is here an additional observation with the 
very interesting data on the evolution of the width of the loss factor recorded during the first run between the $10 \mathrm{kGy}$ irradiated sample and the one cured at higher doses, an indication of the highly heterogeneous distribution of the cross-link density in the network. Moreover, in the sample cured at the lower dose, the right-hand side of the loss factor peak is shifted towards lower temperature, a feature which does not appear in the networks formed from aromatic diacrylates. This is another supporting argument on the reversible formation of domains with higher rigidity under non-equilibrium conditions, likely through additional interchain bridges involving ionic interactions. At the second run, the relaxation profiles are very similar, and subject to possible small artefacts associated with the clamping of specimens in the measuring cell which might explain the small differences in absolute $\mathrm{E}^{\prime}$ and $\mathrm{E}^{\prime \prime}$ moduli.

We compared different methods for determining the glass transition Tg of the epoxy networks, either by differential scanning calorimetry (DSC) or by observation of the $\alpha$ relaxation revealed in the spectra recorded by dynamic mechanical analysis (DMA). In DMA analysis, the thermomechanical relaxation is observed with the onset of the steep decay of the storage modulus $E^{\prime}$, the maximum of the loss modulus $E^{\prime \prime}$ or on peak of the $\tan \delta$.

The plots of Figure 7a were obtained from samples prepared from DGEBA and increasing amounts of TAS- $\mathrm{SbF}_{6}$. The values determined on the basis of the tan $\delta$ values are typically $20^{\circ} \mathrm{C}$ higher than those obtained by calorimetry or by the maximum of $\mathrm{E}^{\prime \prime}$ in DMA spectra, these values being very close for a given material, except for samples of lower conversion and broad distribution of the loss factor, i.e., for highly heterogeneous distribution of cross-link density.

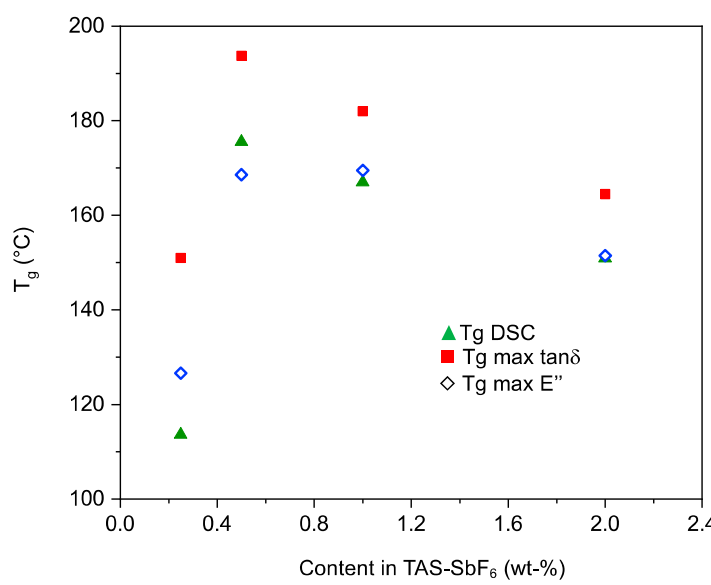

(a)

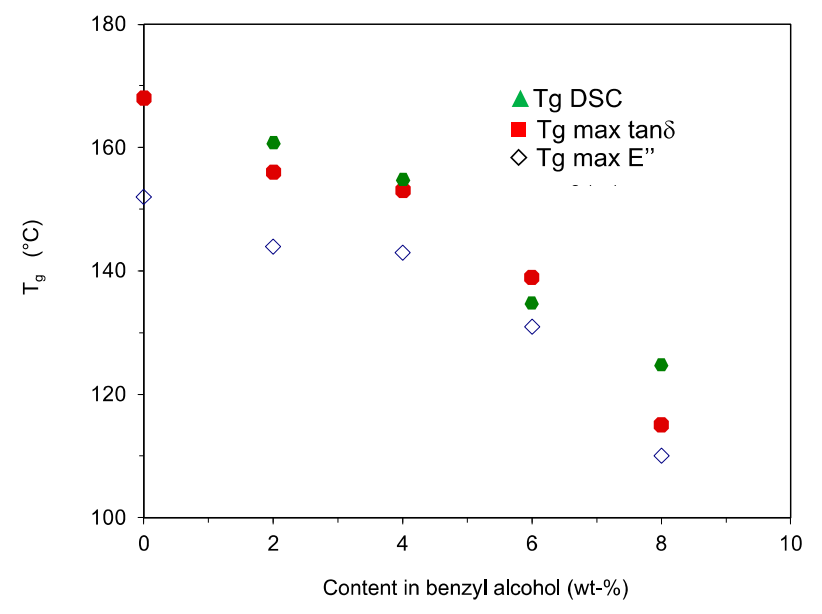

Figure 7. Comparison of the Tg values determined by various methods based on DMA or DSC for (a) DGEBA samples with various contents in $\mathrm{TAS}_{-} \mathrm{SbF}_{6}$ initiator after EB irradiation with 2 passes of $50 \mathrm{kGy}$, and (b) for composite samples based on DGEBA resin sample containing $0.5 \mathrm{wt}-\%$ of $\mathrm{TAS}_{-} \mathrm{SbF}_{6}$ and various contents in benzyl alcohol and $60 \mathrm{wt}-\%$ of powdered silica filler after EB irradiation with 2 passes of $50 \mathrm{kGy}$.

This comparison was also applied to composite samples prepared with the same amount of TAS-SbF 6 ( $0.25 \mathrm{wt}-\%)$ and silica powder as an inert filler $(60 \mathrm{wt}-\%)$ but various contents in benzyl alcohol as a transfer agent. The decrease in Tg shown in Figure $7 \mathrm{~b}$ confirms the efficiency of benzyl alcohol to decrease the cross-link density within the cured networks.

The amount of iodonium salt DAIS-B has a limited effect on the Tg determined as the temperature of the $E^{\prime \prime}$ maximum (Figure 8a). One can, however, observe a slight decrease in $\mathrm{Tg}$ for the four higher concentrations in initiator and harsher curing conditions after $100 \mathrm{kGy}$ irradiation. This can be explained at least in part by a relaxation of ionic interactions produced during the very fast occlusion of active centers and vitrification 
during radiation-initiated curing. The situation is slightly different with the less reactive $\mathrm{TAS} \mathrm{SbF}_{6}$ initiator (Figure $8 \mathrm{~b}$ ). For the two lowest contents in sulfonium salts, the extent of curing after irradiation at $100 \mathrm{kGy}$ has obviously not reached its maximal value. Thermal post-curing during the DMA analysis by thermal treatment in an oven allows to approach completion. Interestingly, the observed $\mathrm{Tg}$ values for $1 \mathrm{wt}-\%$ of $\mathrm{TAS}^{-\mathrm{SbF}_{6}}$ leads to the highest $\mathrm{Tg}$ value observed within these two series.

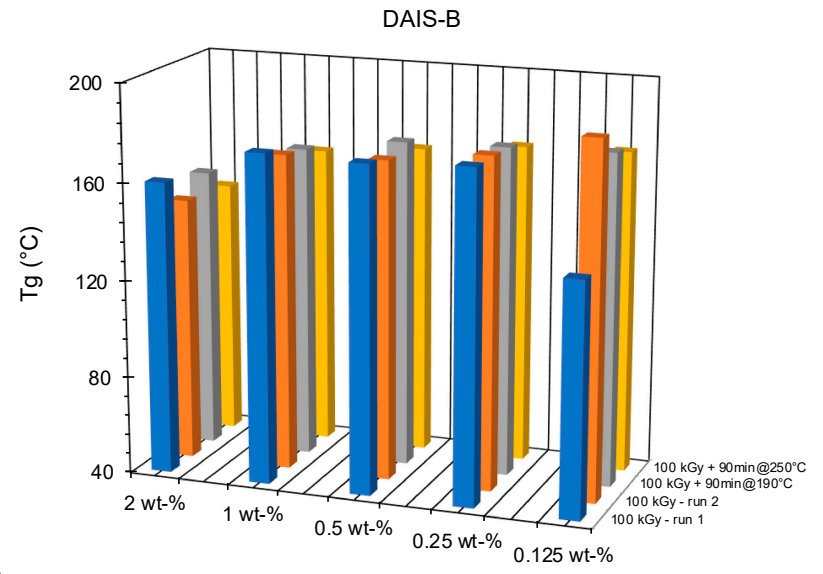

(a) (b)

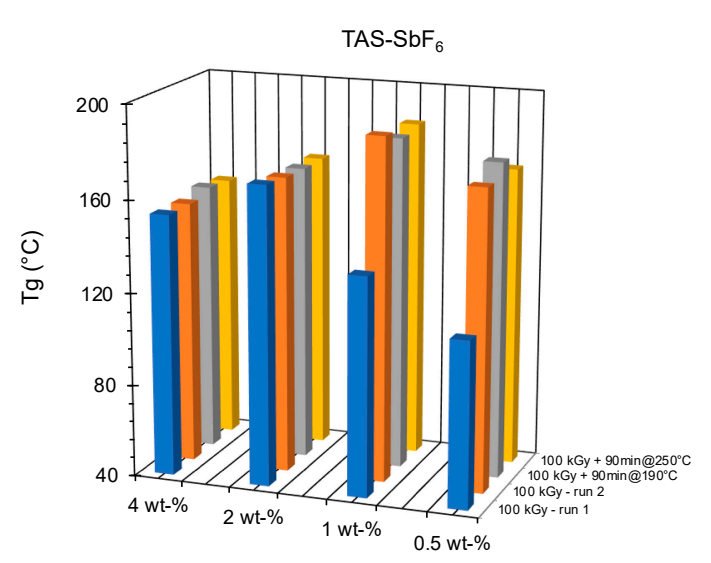

Figure 8. Influence of onium salt nature, DAIS-B (a) or TAS-SbF 6 (b) and concentration and thermal post-curing on the glass transition temperature $\mathrm{Tg}$ ( $\mathrm{T}$ max $\mathrm{E}^{\prime \prime}$ in DMA spectra) for $2 \mathrm{~mm}$ thick plates of DGEBA resin sample cured by EB irradiation with 2 passes of $50 \mathrm{kGy}$.

The need for a precise control of $\mathrm{Tg}$ in specific applications prompted us to further examine the effect of transfer agents in pure matrices.

\subsection{Internal Plasticization Using Reactive Additives}

The presence of hydroxyl groups as impurities or as additives impacts the curing kinetics and, among other features of the material, the network Tg. Chain transfer, which occurs by the AM mechanism, leads to shorter polymer chains and increases the mobility of the reactive species. This results in an acceleration of curing, in a higher final conversion of the monomers, and some decrease of Tg. The plots of Figure 9 illustrate the various possible options to tailor the network structure using the specific reactivity of each type of hydroxyl group [30-32]. The use of PGE as a representative reactive diluent to facilitate the mixing or impregnation processes in composite fabrication also has an influence on the $\mathrm{Tg}$ of the network [33].

\subsection{Heterogeneities}

The curing scenario proposed to describe the gradual build-up of networks by radiationinitiated chain polymerization multi-epoxides is represented in Figure 10. The progress of DGEBA polymerization illustrates the structural variations at the origin of the increase in $\mathrm{Tg}$ and the broadness of the transitions due to the formation of a variety of defects and heterogeneities in cross-link distribution within the networks [34-36].

We have already reported on the importance of these structural defects at the origin of the brittleness of networks obtained by fast chain polymerization of multifunctional monomers, in particular in aromatic diacrylates [37-40].

We recently reported on the advanced understanding of the build-up of thermomechanical properties of networks at nanoscale by probing with new AFM techniques and measuring the peak normal forces, which allow to quantify the local modulus, adhesion, dissipation, and deformation, while simultaneously imaging sample topography of cationically-cured DGEBA and epoxy Novolak resins [22,41]. 


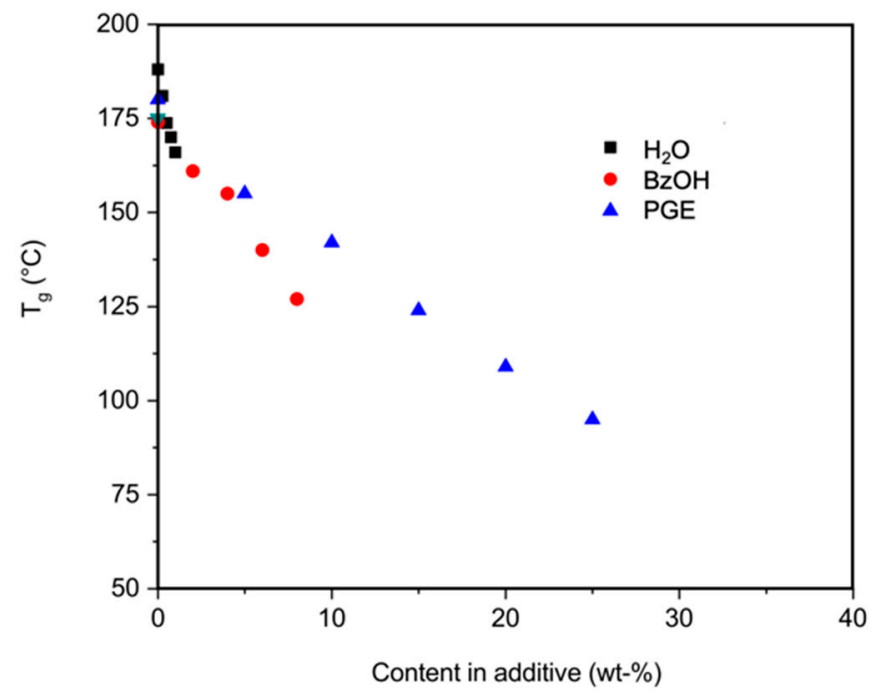

Figure 9. Influence on $\mathrm{Tg}$ (based on $\mathrm{T}_{\alpha}$ determined with the position of $\mathrm{E}^{\prime \prime}$ maximum in DMA spectra) of various contents in additives effective as internal plasticizers of a DGEBA resin sample containing $0.5 \mathrm{wt}-\%$ of DAIS-B after EB irradiation with 4 consecutive $25 \mathrm{kGy}$ passes.

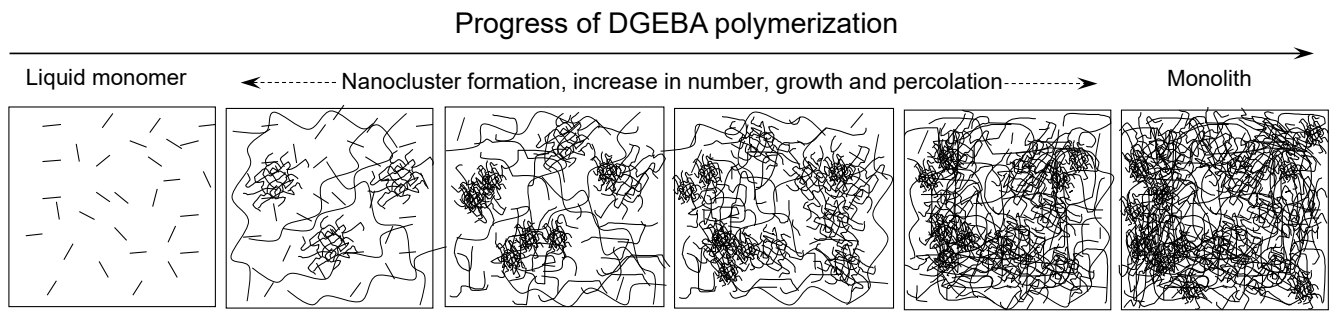

Figure 10. Sketch representing the gradual formation of a monolithic nano-heterogeneous network upon radiation-initiated cationic polymerization DGEBA-based formulations as supported by AFM imaging [22,41].

These observations raise the need for progressing in the control of nanoscale morphology of these different types of networks to improve mechanical properties.

\subsection{Matrix Toughening by Polymerization-Induced Phase Separation}

We prepared simple formulations with $10 \mathrm{wt}$ \% of PES 5003P with respect to the total amount of matrix precursors and a composite with powdered silica representing $60 \mathrm{wt}-\%$ of the whole material to examine the effects of this additive on the cationic polymerization of epoxides. Monomer conversion was measured at various moments of the UV-initiated polymerization of these blends containing $1 \mathrm{wt}-\%$ of TAS-SbF 6 with respect to the matrix. The polymerization profiles of Figure 11 show that there is no significant impact on polymerization kinetics, only a possible screening effect due to UV absorption of UV photons by the PES, but no chemical inhibition, no retardation, and only a slightly slower polymerization rate in the presence of silica powder.

We have therefore explored the possibility to introduce a PES thermoplastic toughening agent into the EB-curable epoxy blends. This approach has marked differences with respect to the conventional toughening methodology applicable to heat-curable systems. The thermodynamics and kinetics of the two modes of curing are strongly different, being extremely brief and starting from RT for radiation processing, and slow and at high temperature for thermal curing. These distinct features are expected to favor the early occurrence of thermoplastic demixion upon radiation-induced polymerization and should limit the growth of the nucleated thermoplastic domains if the system starts vitrifying in the early stage of curing. This combination of favorable factors proved to be particularly efficient for designing acrylate-based radiation-cured matrices and composites [42-45]. 


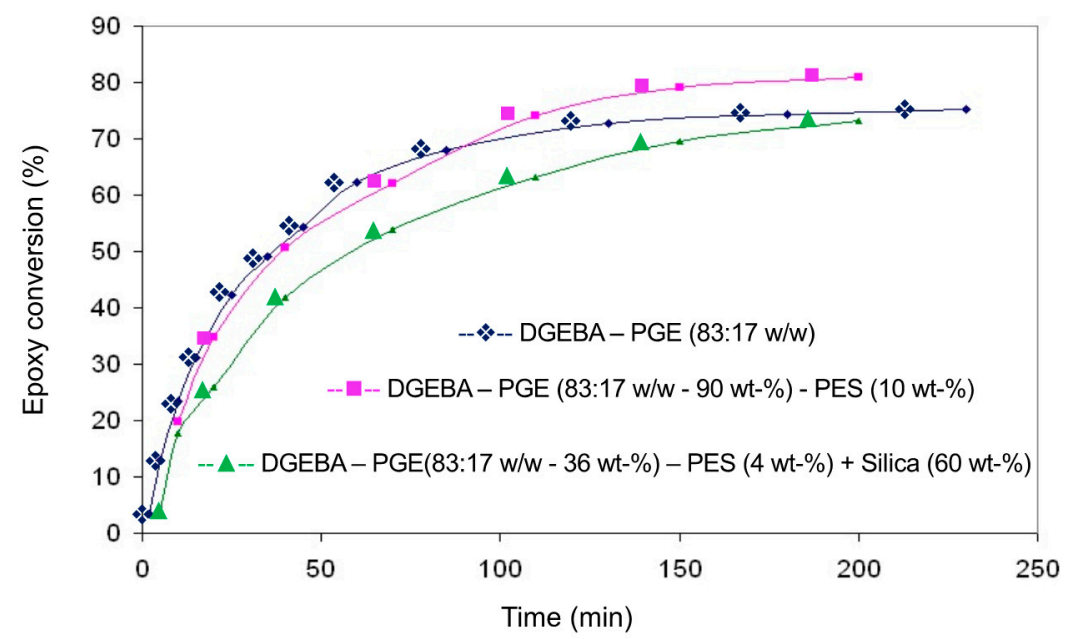

Figure 11. Influence of PES 5003P toughening agent and of silica filler on the kinetic profiles of epoxy group polymerization of DGEBA-PGE blends $(83: 17 w / w)$ containing TAS-SbF 6 as the photo-initiator exposed to $385 \mathrm{~nm}$ UV-LED radiation for 0 to $230 \mathrm{~min}$ with an irradiance of $150 \mathrm{~mW} \mathrm{~cm}{ }^{-2}$.

To compare materials prepared by the two curing process, we implemented the method utilizing a tandem initiator system with a peroxide and an iodonium salt, as presented earlier in Scheme 3. Two series of DGEBA formulations were prepared with poly(THF)-diol as a transfer agent (DGEBA/poly(THF), 93.3:6.7 w/w), various amounts of PES 3006P $(0,7.5$, $10,12.5,15,17.5,19 \mathrm{wt}-\%$ ) and either $0.5 \mathrm{wt}-\%$ DAIS only as the initiator for EB curing, or $0.5 \mathrm{wt}-\%$ DAIS and $0.125 \mathrm{wt}-\%$ Luperox $\mathrm{P}$ for the thermally-induced polymerization [46]. Samples cured in the form of $1 \mathrm{~mm}$ thick plates by both types of activation (for $90 \mathrm{~min}$ at $120{ }^{\circ} \mathrm{C}$ plus $60 \mathrm{~min}$ at $170{ }^{\circ} \mathrm{C}$, or EB dose of $50 \mathrm{kGy}$ ) showed high conversion levels $(>95 \%)$. Comparison of the thermomechanical spectra recorded by DMA analysis of the two series of samples revealed differences that can be interpreted in terms of distinct types of morphology in materials of similar compositions but subject to different curing modes.

We focus on the plots representing the variations of the loss factor $\tan \delta$ as a function of the content in PES and of the curing conditions (Figure 12). In the absence of PES, the epoxy networks present similar DMA spectra, as the peak is centered at $160{ }^{\circ} \mathrm{C}$ for both curing methods. For thermally-cured materials (Figure 12a), the gradual increase of PES in the blend leads to the development of a relaxation peak at $205-210{ }^{\circ} \mathrm{C}$ which corresponds to the $\operatorname{Tg}$ of pure PES $\left(220^{\circ} \mathrm{C}\right)$, the position of the epoxy network transition being almost unchanged, while the transition associated to PES at higher temperature increases in intensity almost proportionally with the PES content and is shifted towards higher temperatures by $10^{\circ} \mathrm{C}$. The system appears as composed of two coexisting phases and with minor cross-solubility. On the contrary, in EB-cured samples (Figure 12b), the transition associated with the epoxy network has its maximum shifted to higher temperatures while the distribution of relaxation temperatures is widened, suggesting the incorporation of a significant amount of PES in the network, with possible formation of a mixed interphase. The peak corresponding to the PES phase appears at the same temperature $\left(200^{\circ} \mathrm{C}\right)$, yet with an enhanced intensity as the amount of PES increases.

Scanning electron microscopy provides complementary information consistent with the observations made by DMA. The micrographs selected for Figure 13 were obtained from the cryo-fractured surfaces of bars prepared from the same two families of blends cured by the two modes of activation. Figure 13a,b shows the fracture profile of the untoughened DGEBA network prepared by EB curing. At low magnification, shear banding is clearly observed together with fragments of ripped material which also appear on the expanded micrograph [47]. In EB-cured materials containing rather low amounts of PES (Figure 13c,d), one observes small PES particles or their imprint in the broken matrix. The particles are evenly distributed with a characteristic size between 100 and $300 \mathrm{~nm}$. In the thermallycured samples, with 7.5 (Figure 13e,f) or $19 \mathrm{wt}$-\% of PES (Figure 13i,j), one observes larger 
spheroidal phase-separated domains ( 0.5 to $10 \mu \mathrm{m}$ in size) with multiphase inclusions observable at larger magnification. With a PES content of $19 \mathrm{wt}-\%$, the spheroidal clusters are more dispersed in size than those in the material containing $7.5 \mathrm{wt}-\%$ of PES. EBcured samples present a different morphology which can be assigned to a co-continuous phase-separated matrix [48]. Such a structure was obtained by a thermal post-treatment of EB-cured samples containing low amounts of PES, as exemplified by the micrographs of Figure $13 \mathrm{c}, \mathrm{d}$ for specimens before thermal post-treatment, to be compared to the pictures of Figure 13g,h obtained from post-cured specimen. Samples with higher contents in PES were obtained directly with the morphology assigned to a co-continuous structure after EB curing (Figure 13k,l) [42].

(a)
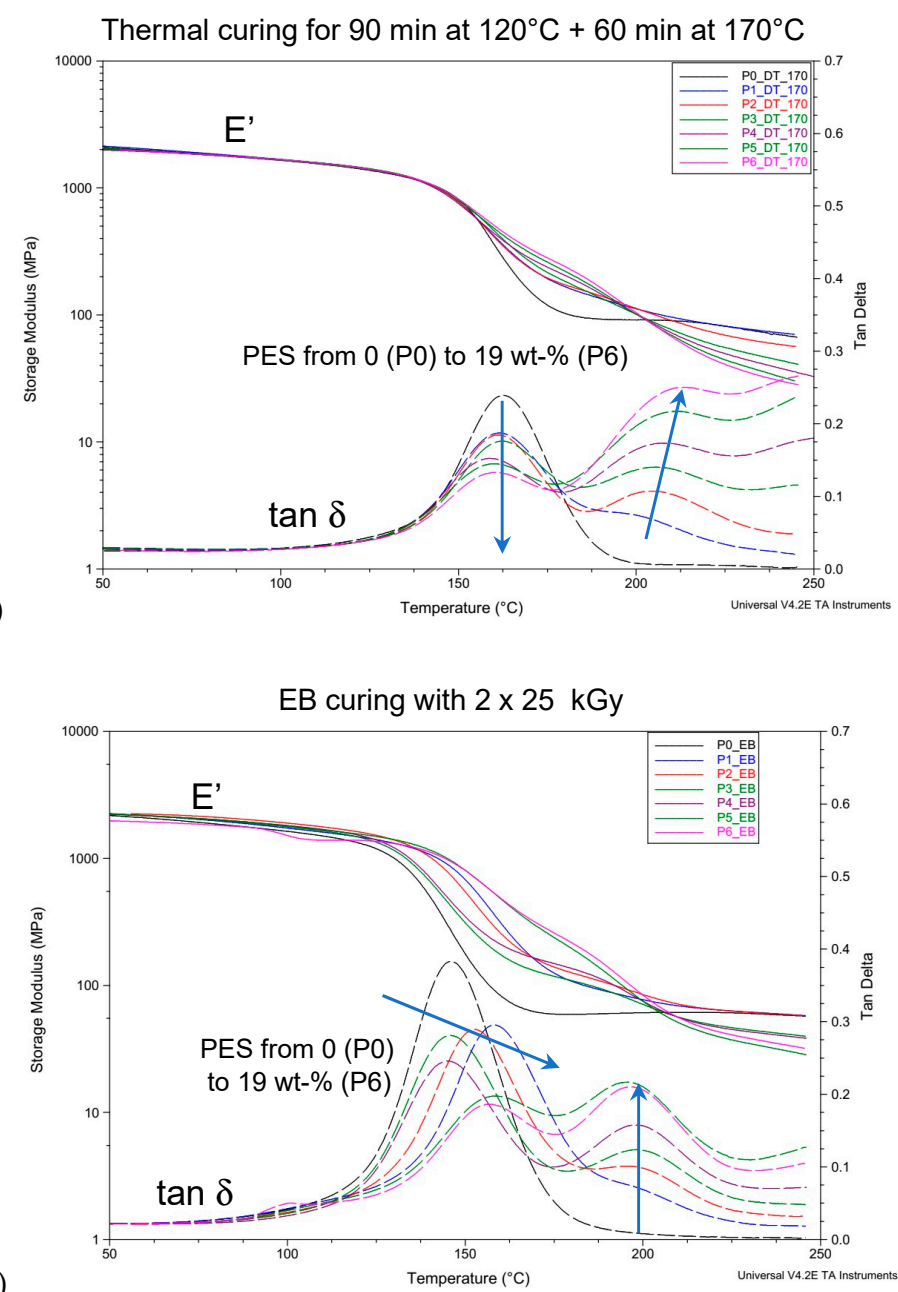

Figure 12. Evolution of the storage modulus $E^{\prime}$ and of the loss factor tan $\delta$ recorded by DMA as a function of the content in PES (0 to $19 \mathrm{wt}-\%$ in samples P0 to P6) and on curing conditions, thermal curing (a) and EB curing (b) of DGEBA/polyTHF-based blends with the appropriate initiator system. 
a)

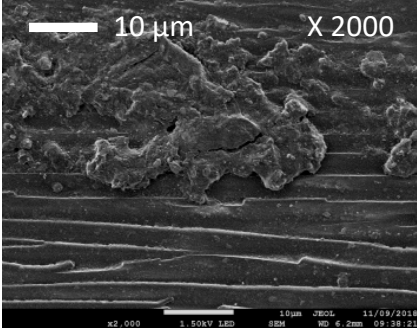

DGEBA-polyTHF-0\%PES-EB

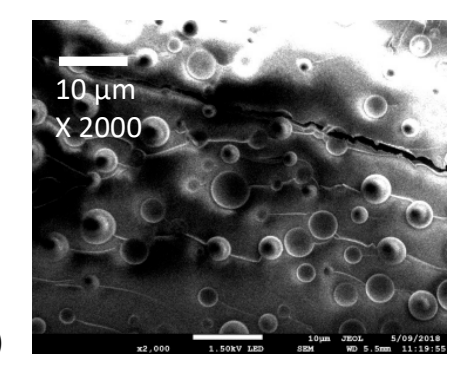

DGEBA-polyTHF-7.5\%PES-Th120+170

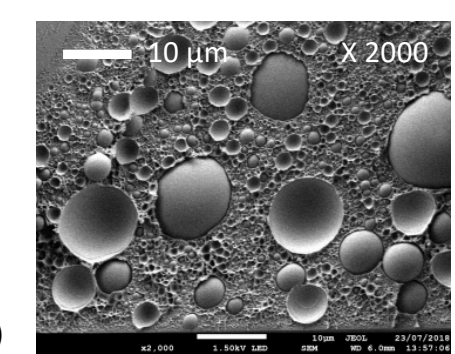

DGEBA-polyTHF-19\%PES-Th120+220 b)

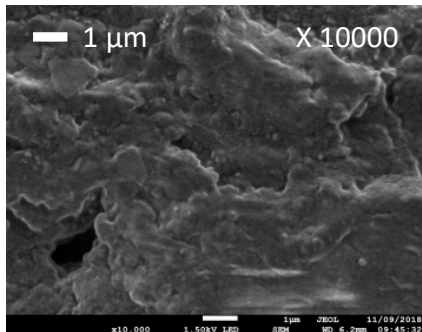

DGEBA-polyTHF-0\%PES-EB

f)

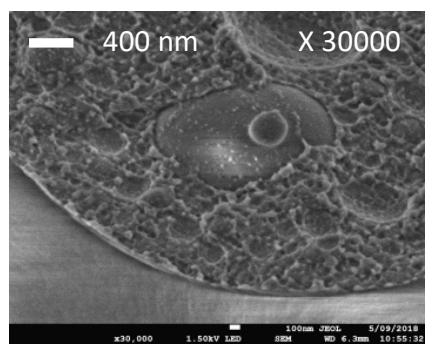

DGEBA-polyTHF-7.5\%PES-Th120+170

j)

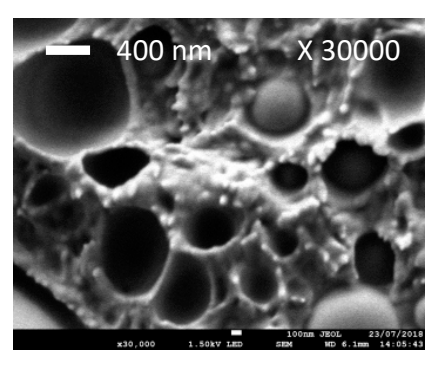

c)

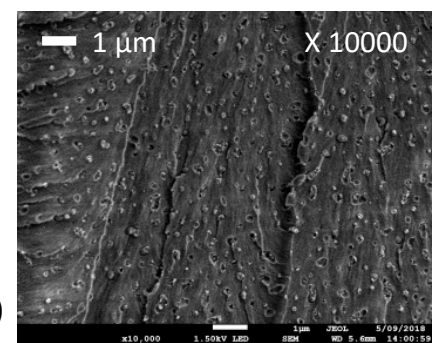

DGEBA-polyTHF-7.5\%PES-EB

g)

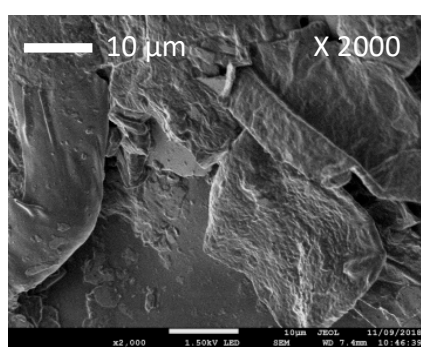

DGEBA-polyTHF-7.5\%PES-EB+170

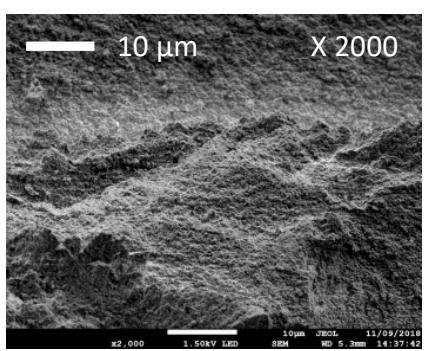

DGEBA-polyTHF-19\%PES-EB+170 d)

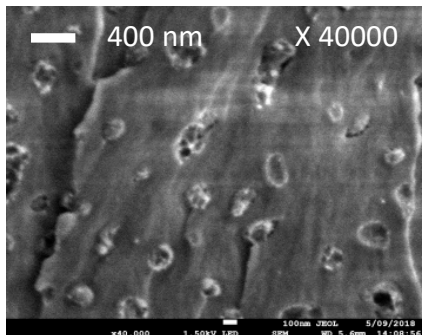

DGEBA-polyTHF-7.5\%PES-EB

h)

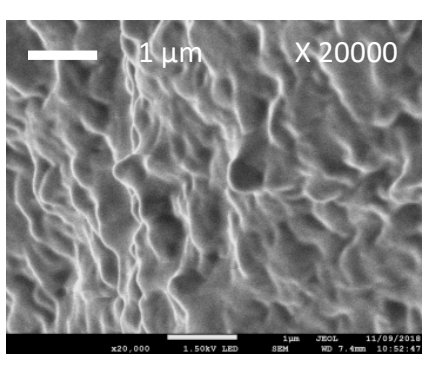

DGEBA-polyTHF-7.5\%PES-EB+170

I)

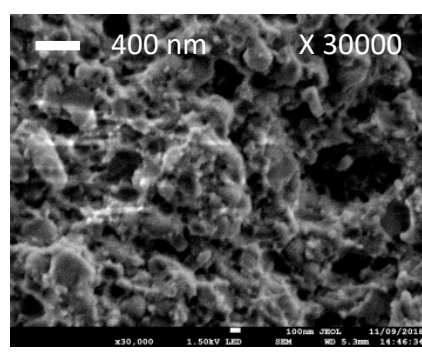

DGEBA-polyTHF-19\%PES-EB+170

Figure 13. SEM micrographs (a-1) revealing the changes in morphology for DGEBA/polyTHF-based matrices depending on the amount of PES introduced as a toughening agent and curing conditions, either by thermal or EB process. Scale bars appear on each micrograph. Indication of magnification factors used during image recording is provided as a qualitative guide for facilitating the comparison between images. 
The overall observations can be rationalized by the following explanations. Cured materials obtained from formulations containing various amounts of PES (from 7.5 to $19 \mathrm{wt}-\%)$ exhibit a biphasic morphology contrasting with the one observed with the PESfree epoxy matrix. The timescale of the chain polymerization is much shorter than for thermal curing. The expected polymerization-induced phase separation process takes place and further develops differently depending on the kinetics and thermodynamical conditions. Because of the sudden vitrification of the system upon EB irradiation of samples initially treated at RT, mass transport required to ensure the growth of phase-separated PES clusters is rapidly constrained by the surrounding network. Thermal curing over long reaction times allows for the formation of large demixed domains, sometimes exhibiting a complex morphology with multiple inclusions of PES in the matrix forming spheroidal composite domains included in the epoxy-rich continuous matrix. The geometrical features of the phase-separated domains are, however, of the same characteristic dimension as that of the heterogeneities revealed in various types of diacrylate networks. Differences in terms of morphology are strongly known to influence the corresponding toughness level. $\mathrm{K}_{\mathrm{Ic}}$ values vary from 1.3 to $2.2 \mathrm{MPa} \cdot \mathrm{m}^{0.5}$ for samples having a PES content varying from 7.5 to $19 \mathrm{wt}-\%$. Further investigations are in progress to gain more information on the structure, morphology and local composition of the two classes of cured materials. Detailed analysis of fracture profiles would also contribute interesting information on the propagation of cracks depending on the morphology. It must be noted that for thermally-cured samples, the large spheroidal PES inclusions seem not to have strong interactions with the epoxy matrix. The co-continuous structure suggested from the micrographs obtained from EB-cured samples containing PES seems to be more beneficial to the expected toughening effect.

EB-cured matrices prepared with similar compositions in toughened materials show optimized critical stress intensity factors of $\left(\mathrm{K}_{\mathrm{IC}}\right) 1.8,1.7$ and $1.6 \mathrm{MPa} \cdot \mathrm{m}^{0.5}$ for DGEBA-PGE $(83: 17 w / w)$ matrices with PES contents of 10,15 and $20 \mathrm{wt}-\%$, respectively, whereas the $\mathrm{K}_{\mathrm{Ic}}$ value is about $0.6 \mathrm{MPa} \cdot \mathrm{m}^{0.5}$ for the unmodified reference resin cured in similar conditions (Figure 14). This confirms the possibility to overcome the inherent brittleness of matrices produced by radiation-induced homopolymerization of multifunctional monomers.

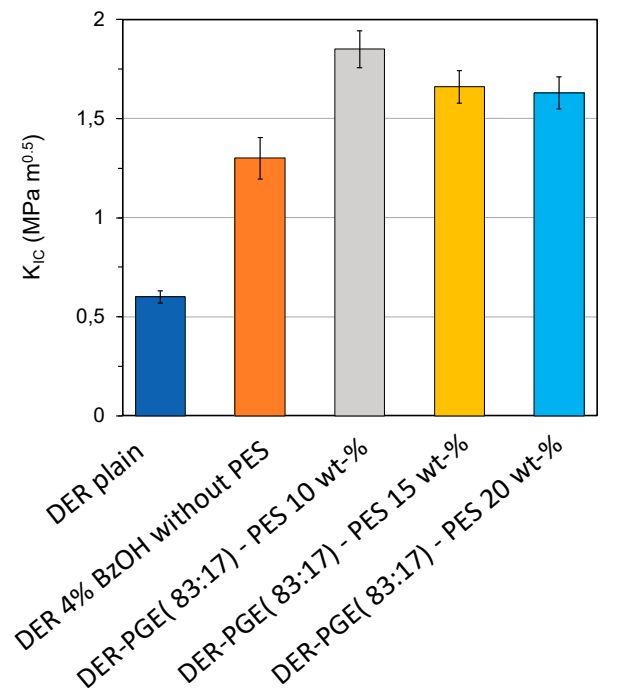

Figure 14. Fracture toughness assessed by $\mathrm{K}_{\mathrm{IC}}$ measurements on various DGEBA-based matrices and depending on the amount of PES introduced as a toughening agent (with $0.5 \mathrm{wt} \%$ of DAIS as initiator, 2 times $50 \mathrm{kGy}$ and post-curing at $130{ }^{\circ} \mathrm{C}$ for $90 \mathrm{~min}$ ).

\section{Conclusions}

Over the recent years, the knowledge on EB and X-ray processing of radiation-curable materials has reached key milestones. Kinetic investigations based on spectroscopic and thermophysical methods provide unique sets of data for describing the gradual evolution 
of materials upon curing and for enhancing the degree of control over of the curing process and over the properties of obtained materials. The present report overviews the recent advances in the understanding of key factors associated with formulation and processing which control the cationic curing of epoxies. A rational approach encompassing basic considerations of radiation physics, radiation chemistry and polymer science led to an experimental investigation where formulation of reactive blends, radiation treatment under well-controlled conditions, and precise monitoring of transformations at molecular, nanoscopic and macroscopic scales provided key information and insight into the relations between chemical composition, optimized radiation treatment and functional performance for the produced materials.

The results presented in this article exemplify a number of formulation and processing options, either based on the chemical composition of the epoxy formulations, particularly the amount and content of onium salts, or on dose effects and thermal post-treatments. Since sufficient thermomechanical properties after extensive curing are required for structural materials, the thermal profile of the reacting medium has to be well-controlled along the whole process to achieve the final degree of conversion and reach the desired glass transition temperature, $\mathrm{Tg}$. In this respect, the intrinsic reactivity of the acidic species generated in situ from the onium salts is a factor of utmost importance. The nature of both onium cation and counter-anion components of these salts has a strong contribution to the observed reactivity.

Based on previous observations of nano-heterogeneities within the formed networks present, we assessed the relevance of one strategy used for high-performance thermosets which consists of adding a high-Tg thermoplastic such as PES to trigger reaction-induced phase separation during polymerization. We evidenced strong differences in terms of matrix morphology depending on the curing method, by thermal or radiation-assisted initiation. Cured materials obtained from formulations containing various amounts of PES (from 7.5 to $19 \mathrm{wt}-\%$ ) revealed the biphasic morphology differing from that of the PES-free epoxy matrix. Thermal curing over long reaction times allows for the formation of large demixed domains exhibiting a complex morphology with multiple inclusion. Conversely, early formation of nano-sized phase-separated domains during the cross-linking polymerization of epoxy blends results in the formation of matrices exhibiting enhanced toughness, with $\mathrm{K}_{\mathrm{Ic}}$ values higher or equal to $1.6 \mathrm{MPa} \cdot \mathrm{m}^{0.5}$, whereas the $\mathrm{K}_{\mathrm{Ic}}$ value is about $0.6 \mathrm{MPa} \cdot \mathrm{m}^{0.5}$ for the unmodified reference resin. The weaknesses of the nano-heterogeneous epoxy matrix seem to be alleviated by the purposely provoked formation of nano-sized clusters of toughening thermoplastic. Further investigation of these systems is currently underway.

Improvement of matrix toughness was presented here, emphasizing this unique feature of radiation processing to initiate fast reactions in systems placed at RT. Solutions for matrix toughening with higher processability and better acceptability in terms of environmental and sanitary requirements are under development. Interactions between mineral fillers, glass or carbon fibers, reinforcing textiles and the cationic matrix are being worked on with promising findings for manufacturing composites with outstanding properties. The next milestones will consist of aggregating the key knowledge and consolidated technological options for reducing processing costs while enhancing composite performances using this cleaner and more productive out-of-autoclave manufacturing.

Author Contributions: Conceptualization, X.C.; methodology, G.R., G.T. and X.C.; formal analysis, G.T., G.R. and X.C.; investigation, G.T. and G.R.; resources, X.C.; data curation, G.R., G.T. and X.C.; writing — original draft preparation, G.T., G.R. and X.C.; writing—review and editing, X.C. All authors have read and agreed to the published version of the manuscript.

Funding: The work presented in this article was partially performed in the frame of the IAEA's Coordinated Research Project "Enhancing the Beneficial Effects of Radiation Processing in Nanotechnology" and of the MIPPI-4D research program granted by Conseil Régional Grand Est and EU-program FEDER. Financial support by CNRS, Conseil Régional Grand Est, Ministry of Higher Education and Research (MESR) to the PIAneT CPER project is gratefully acknowledged. 
Institutional Review Board Statement: Not applicable.

Informed Consent Statement: Not applicable.

Data Availability Statement: Not applicable.

Acknowledgments: The authors are grateful to N. Bercu for his dedication to record sharp and informative SEM images.

Conflicts of Interest: The authors declare no conflict of interest.

\section{References}

1. Beziers, D.; Perilleux, P.; Grenie, Y. Composite structures obtained by ionization curing. Radiat. Phys. Chem. 1996, 48, 171-177. [CrossRef]

2. Berejka, A.J.; Eberle, C. Electron beam curing of composites in North America. Radiat. Phys. Chem. 2002, 63, 551-556. [CrossRef]

3. Janke, C.J.; Dorsey, G.F.; Havens, S.J.; Lopata, V.J. Electron beam curing of epoxy resins by cationic polymerization. SAMPE 1996, 41, 196-206.

4. Wolff-Fabris, F.; Altstädt, V.; Arnold, U.; Döring, M. Electron Beam Curing of Composites; Carl Hanser Verlag: Munich, Germany, 2010.

5. Fouassier, J.P.; Fouassier, J.P. Radiation Curing in Polymer Science and Technology; Fouassier, J.P., Rabek, J.F., Eds.; Elsevier Applied Science: Amsterdam, The Netherlands, 1993; Volumes 1-3.

6. Ferry, M.; Ngono-Ravache, Y.; Aymes-Chodur, C.; Clochard, M.C.; Coqueret, X.; Cortella, L.; Pellizzi, E.; Rouif, S.; Esnouf, S. Ionizing radiation effects in polymers. In Reference Module in Materials Science and Materials Engineering; Hashmi, S., Ed.; Elsevier: Oxford, UK, 2016; pp. 1-28.

7. Al-Mosawl, A.I.; Ammosh, H.; Salamain, A.J. Properties of Composite Materials Databook; LAP LAMBERT Academic Publishing: Saarbrücken, Germany, 2012.

8. Landel, R.F.; Nielsen, L.E. Mechanical Properties of Polymers and Composites, 2nd ed.; Kindle Edition; CRC Press: Boca Raton, FL, USA, 1993.

9. Pascault, J.P.; Williams, R.J.J. Epoxy Polymers: New Materials and Innovations; Wiley-VCH Verlag: Mannheim, Germany, 2010.

10. Belgacem, M.N.; Gandini, A. Monomers, Polymers and Composites from Renewable Resources; Belgacem, M.N., Gandini, A., Eds.; Elsevier: Amsterdam, The Netherlands, 2008.

11. Crivello, J.V. UV and electron beam-induced cationic polymerization. Nucl. Instrum. Methods Phys. Res. Sect. B 1999, 151, 8-21. [CrossRef]

12. Sangermano, M. Advances in cationic photopolymerization. Pure Appl. Chem. 2012, 84, 2089-2101. [CrossRef]

13. Sipani, V.; Kirsch, A.; Scranton, A.B. Dark cure studies of cationic photopolymerizations of epoxides: Characterization of kinetic rate constants at high conversions. J. Polym. Sci. Pol. Chem. 2004, 42, 4409-4416. [CrossRef]

14. Raghavan, J.; Baillie, M.R. Electron beam curing of polymer composites. Polym. Compos. 2000, 21, 619-629. [CrossRef]

15. Crivello, J.V. Advanced curing technologies using photo- and electron beam induced cationic polymerization. Radiat. Phys. Chem. 2002, 63, 21-27. [CrossRef]

16. Przybytniak, G.; Nowicki, A.; Mirkowski, K.; Stobiński, L. Gamma-rays initiated cationic polymerization of epoxy resins and their carbon nanotubes composites. Radiat. Phys. Chem. 2016, 121, 16-22. [CrossRef]

17. Emmi, S.S.; Corda, U.; Fuochi, P.; Lavalle, M.; Alessi, S.; Spadaro, G. Pulse radiolysis and theoretical investigation on the initial mechanism of the e-beam polymerization of epoxy resins. The results obtained on (phenoxymethyl)oxirane. Radiat. Phys. Chem. 2007, 76, 1251-1256. [CrossRef]

18. Chmielewski, A.G.; Zimek, Z. Electron Accelerators for Research, Industry and Environment: The INCT Perspective; Institute of Electronic Systems, Warsaw University of Technology: Warsaw, Poland, 2019.

19. Seuntjens, J.P.; Strydom, W.; Shortt, K.R. Dosimetric principles, quantities and units. In Radiation Oncology Physics: A Handbook for Teachers and Students; IAEA Publications: Vienna, Austria, 2012.

20. Dabestani, R.; Ivanov, I.N.; Sands, J.M. Application of time resolved pulse radiolysis technique in the investigation of the mechanism of epoxy resins cationic polymerization. SAMPE 2002, 47, 51-64.

21. Pascault, J.P.; Williams, R.J.J. Glass transition temperature versus conversion relationships for thermosetting polymers. International Organization for Standardization. J. Polym. Sci. Polym. Phys. 1990, 28, 85-95. [CrossRef]

22. Ranoux, G.; Molinari, M.; Coqueret, X. Thermo-mechanical properties and structural features of diglycidyl ether of bis phenol A cationically cured by electron beam radiation. Radiat. Phys. Chem. 2012, 81, 1297-1302. [CrossRef]

23. ISO 13586:2018(E); Plastics_-Determination of fracture toughness ( $\mathrm{G}_{\mathrm{IC}}$ and $\mathrm{K}_{\mathrm{IC}}$ )—Linear elastic fracture mechanics (LEFM) approach. International Standard Organization: Geneva, Switzerland, 2018.

24. Crivello, J. Redox initiated cationic polymerization: Reduction of triarylsulfonium salts by silanes. Silicon 2009, 1, 111-124. [CrossRef]

25. Romanczyk, P.P.; Kurek, S.S. Reliable reduction potentials of diaryliodonium cations and aryl radicals in acetonitrile from high-level ab initio computations. Electrochim. Acta 2020, 351, 136404. [CrossRef]

26. Crivello, J.V.; Dietliker, K.; Bradley, G. Photoinitiators for free radical, cationic and anionic photopolymerization. In Chemistry and Technology for UV; Bradley, G., Ed.; John Wiley \& Sons: Chichester, UK, 1998. 
27. Voytekunas, V.Y.; Ng, F.L.; Abadie, M.J.M. Kinetics study of the UV-initiated cationic polymerization of cycloaliphatic diepoxide resins. Eur. Polym. J. 2008, 44, 3640-3649. [CrossRef]

28. Defoort, B.; Defoort, D.; Coqueret, X. Electron-beam initiated polymerization of acrylate compositions, 2. Simulation of thermal effects in thin films. Macromol. Theor. Simul. 2001, 9, 725-734. [CrossRef]

29. Degrand, H.; Cazaux, F.; Coqueret, X.; Defoort, B.; Boursereau, F.; Larnac, G. Thermal effects on the network structure of diglycidyl ether of bisphenol-A polymerized by electron-beam in the presence of an iodonium salt. Radiat. Phys. Chem. 2003, 68, 885-891. [CrossRef]

30. Crivello, J.V.; Ortiz, R.A. Benzyl alcohols as accelerators in the photoinitiated cationic polymerization of epoxide monomers. J. Polym. Sci. Part A Polym. Chem. 2002, 40, 2298-2309. [CrossRef]

31. Bongiovanni, R.; Malucelli, G.; Sangermano, M.; Priola, A. Preparation of coatings via cationic photopolymerisation: Influence of alcoholic additives. Macromol. Symp. 2002, 187, 481-492. [CrossRef]

32. Lee, J.; Palmese, G.R. Cationic Polymerization of glycidyl ethers and furans: Improved electron beam and UV cured epoxy networks. SAMPE 2005, 50, 663-677.

33. Allen, N.S.; Edge, M. UV and electron beam curable pre-polymers and diluent monomers: Classification, preparation and properties. In Radiation Curing in Polymer Science and Technology, Fundamentals and Methods; Fouassier, J.P., Rabek, J.F., Eds.; Elsevier Applied Science: London, UK, 1993; Volume 1, pp. 225-262.

34. Lorenzo, D.F.; Seiffert, S. Nanostructural heterogeneity in polymer networks and gels. Polym. Chem. 2015, 6, 5515-5528. [CrossRef]

35. Dušek, K.; Galina, H.; Mikes, J. Features of network formation in the chain crosslinking (co)polymerization. Polym. Bull. 1980, 3, 19-25. [CrossRef]

36. Dušek, K. Inhomogeneities induced by crosslinking in the course of crosslinking copolymerization. In Polymer Networks Structure and Mechanical Properties; Chompff, A.J., Newman, S., Eds.; Springer: Berlin/Heidelberg, Germany, 1971.

37. Chuda, K.; Smolinski, W.; Defoort, B.; Rudz, W.; Gawdzik, B.; Rayss, J.; Coqueret, X. Effects of vitrification on the isothermal polymerization of acrylate blends under radiation. Polimery (Wars. Pol.) 2004, 49, 505-513. [CrossRef]

38. Coqueret, X.; Krzeminski, M.; Ponsaud, P.; Defoort, B. Recent advances in electron-beam curing of carbon fiber-reinforced composites. Radiat. Phys. Chem. 2009, 78, 557-561. [CrossRef]

39. Krzeminski, M.; Molinari, M.; Troyon, M.; Coqueret, X. Calorimetric characterization of the heterogeneities produced by the radiation-induced crosslinking polymerization of aromatic diacrylates. Macromolecules 2010, 43, 3757-3763. [CrossRef]

40. Krzeminski, M.; Molinari, M.; Troyon, M.; Coqueret, X. Characterization by atomic force microscopy of the nanoheterogeneities produced by the radiation-induced crosslinking polymerization of aromatic diacrylates. Macromolecules 2010, 43, 8121-8127. [CrossRef]

41. Kowandy, C.; Ranoux, G.; Walo, M.; Vissouvanadin, B.; Teyssedre, G.; Laurent, C.; Berquand, A.; Molinari, M.; Coqueret, X. Microstructure aspects of radiation-cured networks: Cationically polymerized aromatic epoxy resins. Radiat. Phys. Chem. 2018, 143, 20-28. [CrossRef]

42. Krzeminski, M.; Molinari, M.; Defoort, B.; Coqueret, X. Nanoscale heterogeneities in radiation-cured diacrylate networks: Weakness or asset? Radiat. Phys. Chem. 2013, 84, 79-84. [CrossRef]

43. Krzeminski, M.; Defoort, B.; Coqueret, X. Increase in the Toughness of a Material Achieved by Means of a Curable Composition Including at Least One Vinyl Ester Monomer. Patent US/2012/0277383A1, 21 December 2013.

44. Krzeminski, M.; Defoort, B.; Coqueret, X. Curable Compositions Allowing to Obtain Materials Having an Optimised Performance, and Materials Obtained from Said Compositions. Patent US/2014/0336341A1, 13 November 2014.

45. Coqueret, X.; Krzeminski, M.; Gawdzik, B.; Rudz, W. Compositions Containing a Vinyl Ester Resin That Can Be Used to Obtain Materials Having an Optimized Performance, and Materials Obtained from Said Compositions. Patent WO/2013/083564, 13 June 2013.

46. Coqueret, X.; Ranoux, G.; Mhanna, A.; Hassanzadeh, M.; Ohl, B. Curable Epoxy Resin Compositions. Patent EP/3296340B1, 14 August 2019.

47. Bucknall, C.B.; Gomez, C.M.; Quintard, I. Phase separation from solutions of poly(ether sulfone) in epoxy resins. Polymer 1994, 35, 353-359. [CrossRef]

48. Francis, B.; Thomas, S.; Thomas, S.P.; Ramaswamy, R.; Lakshmana Rao, V. Diglycidyl ether of bisphenol-A epoxy resin-polyether sulfone/polyether sulfone ether ketone blends: Phase morphology fracture toughness and thermo-mechanical properties. Colloid Polym. Sci. 2006, 285, 83-93. [CrossRef] 